\title{
Polymerization capability of simplified dental adhesives with camphorquinone, phenyl- propanedione and bis-alkyl phosphine photoinitiators
}

Boniek Castillo Dutra Borges ${ }^{1}$, Rodolfo Xavier de Sousa-Lima', Géssica Dandara Medeiros de Souza', Ana Carla Bezerra de Carvalho Justo-Fernandes ${ }^{1}$, Letícia Virgínia de Freitas Chaves ${ }^{1}$, Eduardo José Carvalho Souza-Junior'², Isauremi Vieira de Assunção

1 Universidade Federal do Rio Grande do Norte (UFRN), Departamento de Dentística, Av Sen Salgado Filho 1787 - Lagoa Nova, Natal, RN, 59056-000, Brazil.

2FAIPE School, Rua dos Girassóis 86 - Jardim Cuiabá, Cuiabá, MT, 78043-132, Brazil.
Corresponding author: Rodolfo Xavier de Sousa-Lima Av Sen Salgado Filho 1787, Natal, RN, 59056-000, Brazil. Tel./fax +55 843215 4101. E-mail address: rodolfo_xsl@hotmail.com

Received: March 06, 2018

Accepted: July 09, 2018
Aim: this study aimed to evaluate the degree of conversion (DC) exhibited by novel formulations of dental adhesive systems including camphorquinone (CQ), phenyl-propanedione (PPD), and bis-alkyl phosphine oxide (BAPO) when cured by mono- or polywave light emitting diodes (LEDs). Methods: an adhesive model was formulated by mixing hydroxyethyl methacrylate (HEMA, 40 wt\%) and bisphenol A glycidyl dimethacrylate (BisGMA, $60 \mathrm{wt} \%$ ) in ethanol (30 wt\%). Five materials were then formulated by adding the following photoinitiators: $\mathrm{CQ}$ (1 mol\%), CQ/PPD (0.5/0.5 mol\%), CQ/BAPO (0.5/0.5 mol\%), PPD (1 mol\%), and BAPO (1 mol\%). The DC for each material was measured with Fourier transform infrared spectroscopy. Analysis of variance and Tukey's post-hoc test were used to analyze the data $(p<0.05)$. Results: Except for $C Q$, the photoinitiators provided a significantly higher DC in the adhesive systems following photoactivation with a polywave LED. Conclusion: The use of alternative photoinitiators and a polywave LED improved the DC of the adhesive systems examined.

Keywords: Spectroscopy, fourier transform infrared. Dental materials. Dental cements. 


\section{Introduction}

Dental adhesives are materials composed of monomers with both hydrophilic and hydrophobic groups, photoinitiators, inhibitors or stabilizers, solvent and, in some cases, inorganic fillers ${ }^{1}$. The classical model of dental adhesives is available in three application steps (acid etching, priming and bonding). Over time, the need to reduce the number of clinical steps during application of dental adhesives required the emergence of simplified materials to reduce the chair time. In this way, adhesives systems have gone through several changes in recent years, with the creation of new monomers and photoinitiating molecules, in an attempt to simplify bonding procedures without compromising adhesion to tooth substrates².

In general, the adhesive performance depends on the degree of conversion (DC) so that a high DC is fundamental to improving resistance of material degradation under in vivo clinical conditions. Low DC of dental adhesives is associated with high water sorption/solubility, as well as low bond strength values, low mechanical properties, increased permeability, and even the occurrence of phase separation ${ }^{3}$. This conversion could be affected by many factors, including the photoinitiator systems and light wavelength of the curing unit used ${ }^{4}$. Thus, the development of simplified adhesive systems capable to show increased DC is detrimental.

The most contemporary adhesive systems are activated by light within the blue band of the spectrum (400-500 nm) and they use camphorquinone (CQ) as a photoinitiator $^{5}$. CQ is a solid yellow compound with an unbleachable chromophore group that can absorb light in the spectral range of approximately $400-500 \mathrm{~nm}$, with a peak near $470 \mathrm{~nm}^{6,7}$. However, the yellow hue characteristic of CQ compromises its aesthetic performance and photoinitiators eventually degrade over time ${ }^{5,8}$. Therefore, alternative photoinitiators such as phenyl propanodione (PPD), and bis-alkyl phosphine oxide (BAPO) have been investigated in an attempt to replace CQ or decrease the amount of CQ into dental materials without compromising the $\mathrm{DC}^{6,9,10}$.

Most of the alternative photoinitiators that have been studied have an absorption peak in the ultraviolet region which extends slightly into the visible light spectrum $(380-420 \mathrm{~nm})^{5,11}$. Both the spectrum emitted by a light source and the absorption capacity of a photoinitiator have an effect on the polymerization process of composites, thereby influencing their properties ${ }^{5,11,12}$. As a result, cure efficiency can be compromised when narrowband light-emitting diodes (LEDs), such as conventional monowave LEDs are used, since these LEDs do not have light emission in the violet wavelength range $5,11,13$. Thus, the ability of conventional LEDs to activate photoinitiators that respond to ultraviolet light is limited. However, polywave LEDs emit dual peaks, with one additional peak being near $405 \mathrm{~nm}^{14-16}$, and this allows these LEDs to activate photoinitiators such as PPD and BAPO

In this way, the aim of this study was to evaluate the degree of conversion (DC) of novel formulations of dental adhesive systems including CQ, PPD, and BAPO when cured by mono- or polywave LEDs in order to test the hypothesis that the use of alternative photoinitiators and photoactivation with a polywave LED can lead to an increased DC. 


\section{Materials and methods}

\section{Experimental design}

The response variable evaluated in this in vitro study was DC. Five photoinitiators (CQ, CQ/PPD, CQ/BAPO, PPD, and BAPO) (Table 1) and two types of LEDs (monowave and polywave) (Table 2) were tested.

Table 1. Characteristics of photoinitiators used in this study.

\begin{tabular}{lccc}
\hline Photoinitiator & $\begin{array}{c}\text { Absorption spectrum } \\
\text { range }(\mathrm{nm})\end{array}$ & $\begin{array}{c}\text { Absorption intensity } \\
\text { peak }(\mathrm{nm})^{[7]}\end{array}$ & $\begin{array}{c}\text { Molar extinction } \\
\text { coeficiente }(\mathrm{L} / \mathrm{mol} \mathrm{cm})^{[7]}\end{array}$ \\
\hline $\mathrm{CQ}^{*}$ & $400-500^{[7]}$ & 470 & $28 \pm 2$ \\
\hline PPD $^{* *}$ & $350-480^{[17]}$ & 398 & $150 \pm 10$ \\
\hline BAPO $^{* \star *}$ & $365-416^{[7]}$ & 370 & $300 \pm 10$ \\
\hline${ }^{*}$ Camphorquinone; ${ }^{* *}$ Phenyl-Propanedione; ${ }^{* * *}$ Bis-Alkyl Phosphine Oxide
\end{tabular}

Table 2. Technical details of light emitting diodes used in this study according to the manufacturers.

\begin{tabular}{lcccc}
\hline Comercial name/ Manufacturer & Classification & Spectrum range & Intensity peaks & Irradiance \\
\hline $\begin{array}{l}\text { Bluephase G2, Ivoclar Vivadent, } \\
\text { Schaan, Liechtenstein }\end{array}$ & Polywave & $\begin{array}{c}385-515 \mathrm{~nm} \\
(380-420 ; \\
420-490)\end{array}$ & $\begin{array}{l}405 \mathrm{~nm} \\
460 \mathrm{~nm}\end{array}$ & $1200 \mathrm{~mW} / \mathrm{cm}^{2}$ \\
\hline Radii Cal, SDI, Victoria, Australia. & Monowave & $440-480 \mathrm{~nm}$ & $460 \mathrm{~nm}$ & $1313 \mathrm{~mW} / \mathrm{cm}^{2}$ \\
\hline
\end{tabular}

\section{Formulation of the experimental adhesive systems}

Bisphenol A glycidyl dimethacrylate (BisGMA) and hydroxyethyl methacrylate (HEMA) (60:40 wt\%) (Sigma-Aldrich, St. Louis, MO, USA) were mixed with ethanol (30 wt\% $)^{17}$. Then, five different materials were generated with the addition of these various photoinitiators: CQ (1 mol\%), CQ/PPD (0.5/0.5 mol\%), CQ/BAPO (0.5/0.5 mol\%), PPD (1 mol\%), and BAPO (1 mol\%). Ethyl 4-(dimethylamino)benzoate (EDMAB) (Sigma-Aldrich) (1 mol\%) was added to all of the prepared formulations to serve as a co-initiator.

\section{DC evaluation}

DC was evaluated with a Fourier transform infrared/attenuated total reflectance instrument (FTIR/ATR) (Spectrum 100, PerkinElmer, Shelton, CT, USA) at $24^{\circ} \mathrm{C}$ under $64 \%$ relative humidity. One drop of each adhesive system $(n=10$ per photoinitiator and LED) was applied to the ATR surface and the solvent was evaporated for $10 \mathrm{~s}$. Then, a thin glass plate $(0.5 \mathrm{~mm}$ thick) was placed on the material and it was photoactivated for $10 \mathrm{~s}$ using a LED. The irradiance of the LEDs were measured by using a computer-controlled spectrometer (USB2000, Ocean Optics, Dunedin, USA) and was integrated using Origin 6.0 software (OriginLab, Northampton, USA).

The absorption spectra of both the nonpolymerized and polymerized adhesive systems prepared were obtained between 4000 and $650 \mathrm{~cm}^{-1}$ with 32 scans at $4 \mathrm{~cm}^{-1}$. Intensities of the aliphatic carbon-to-carbon double-bond absorbance peak (located 
at $1638 \mathrm{~cm}^{-1}$ ) and the aromatic component (located at $1608 \mathrm{~cm}^{-1}$; reference peak) were recorded. DC (\%) was calculated using the following equation 18 :

$$
D C(\%)=100 \times\left[1-\left(\frac{R \text { polymerized }}{R \text { nonpolymerized }],}\right)\right],
$$

where $R$ represents the ratio between the absorbance peaks at $1638 \mathrm{~cm}^{-1}$ and $1608 \mathrm{~cm}^{-1}$.

\section{Statistical analysis}

Two-way analysis of variance (ANOVA) and Tukey's post-hoc test were used $(p<0.05)$.

\section{Results and Discussion}

There were statistically significant differences in the interaction between photoinitiators $x$ LEDs $(p<0.01)$. Table 3 shows the intergroup comparisons. Only the CQ adhesive system achieved a similar mean DC as the samples were photoactivated by Radii Cal and Bluephase G2, so that Bluephase G2 provided a higher mean DC than Radii Cal to the other adhesive systems. Bluephase G2 provided similar mean DC between adhesive systems. Radii Cal provided the highest DC to the CQ adhesive system, while the lowest DC was observed for the CQ/BAPO and BAPO adhesive systems. Thus, the hypothesis that the use of alternative photoinitiators that and photoactivation with a polywave LED can lead to an increased DC was accepted.

Table 3. Degree of conversion (\%) means (standard-deviation) of dental adhesive systems according to the photoinitiator system and the curing light.

\begin{tabular}{lcc}
\hline \multirow{2}{*}{ Photoinitiator system } & \multicolumn{2}{c}{ Light emitting diode } \\
\cline { 2 - 3 } & Radii Cal & Bluephase G2 \\
\hline CQ & $77.8(6.8) \mathrm{aA}$ & $77.3(14.1) \mathrm{aA}$ \\
\hline $\mathrm{CQ} / \mathrm{PPD}$ & $48.8(7.4) \mathrm{bB}$ & $71.6(7.7) \mathrm{aA}$ \\
\hline $\mathrm{CQ} / \mathrm{BAPO}$ & $31.5(11.5) \mathrm{cB}$ & $74.1(6.9) \mathrm{aA}$ \\
\hline PPD & $47.2(4.0) \mathrm{bB}$ & $74.2(6.4) \mathrm{aA}$ \\
\hline BAPO & $27.6(3.9) \mathrm{cB}$ & $81.6(6.5) \mathrm{aA}$
\end{tabular}

Means followed by different capital letters indicate statistically significant differences between curing lights for the same photoinitiator $(p<0.05)$. Means followed by different lower case letters indicate statistically significant differences among photoinitiator systems for the same curing light $(p<0.05)$.

The DC of an adhesive system is influenced by the activity of photoinitiators and the wavelength and intensity of the curing light that is applied ${ }^{19}$. In this study, only the adhesive systems that included CQ exhibited a similar DC between the samples that were photoactivated by Radii Cal and Bluephase G2. Conventional monowave LEDs, such as Radii Cal, have an emission band in the visible region which results in the emission of a single peak in a narrow spectral band ${ }^{20}$. In contrast, Bluephase $\mathrm{G} 2$ is a dual peak LED that provides additional light with a spectrum that nearly includes $405 \mathrm{~nm}^{14,15}$. CQ is activated within the visible light spectrum and has a peak absorbance near $470 \mathrm{~nm}^{6,7}$. Based on the data collected, it appears that both monowave and polywave LEDs are able to excite CQ. This corroborates with that found by Segreto et al. ${ }^{21}$ (2016) who tested different photoinitiator units and photoinitiator systems and concluded that both types of light (mono and polywave) are capable of activating CQ and PPD. 
Unlike CQ, the adhesive systems formulated with CQ/PPD, CQ/BAPO, PPD, and BAPO exhibited a higher DC when they were photoactivated by Bluephase G2 than with Radii Cal. Alternative photoinitiators such as PPD and BAPO have an absorption peak in the ultraviolet region (100-400 nm) ${ }^{22}$, specifically at $398 \mathrm{~nm}$ and $370 \mathrm{~nm}$, respectively ${ }^{5}$. Thus, photoactivation with a polywave LED could promote an increased excitation of these photoinitiators, thereby increasing the generation of free radicals that initiate the polymerization reaction. However, the monowave LED, Radii Cal, provided a higher DC for the PPD adhesive system than the BAPO system. Thus, it is likely that PPD can also absorb light in the visible range of the light spectrum ${ }^{20}$, thereby accounting for the greater excitation of PPD by Radii Cal compared with BAPO. The results indicated that PPD was a viable alternative in the formulation of experimental adhesives, observing that it presents greater reactivity independent of the type of photoinitiator unit ${ }^{21}$.

Despite the fact that BAPO is a Norirish Type I photoinitiator which generates free radicals via a photocleavage process that does not require a co-initiator ${ }^{23}$, a tertiary amine EDMAB was added to the BAPO-containing materials in the present study. EDMAB is capable of reacting with the oxygen that is dissolved in the monomer, thereby reducing an oxygen-mediated inhibition of polymerization ${ }^{23}$. Since CQ employs a mechanism that predominantly involves abstraction of a proton from the amine hydrogen, and PPD can undergo photocleavage and proton abstraction of the amine ${ }^{24}$, EDMAB was included with all of the photoinitiators tested so the same conditions would be compared.

The findings obtained in this study are of great relevance, since DC is the main physical property related to other biological, physical and mechanical properties such as sorption and solubility, long-term stability of the hybrid layer ${ }^{25}$, liberation of residual monomers and preservation of the complex dentin pulp ${ }^{4}$, bond strength to dentin ${ }^{9}$, elastic modulus and flexural strength of dental adhesives ${ }^{26}$. Confirming this statement, Schneider et al. ${ }^{27}$ (2009) evaluated the effect of the photoinitiator type on the maximum rate of polymerization $(R(p)(\max )$ ), stress development (final stress and maximum rate, $\mathrm{R}($ stress)(max)), $\mathrm{DC}$ and cross-link density (CLD) of materials containing $C Q, P P D$ or $C Q / P P D$ and conclude that $C Q / P P D$ reduced the $R(p)(\max )$ and $\mathrm{R}$ (stress)(max) without a reduction in DC and CLD. In this way, the use of alternative photoinitiator systems could be a promising way to reduce the stress developed during the composite's polymerization without affecting the final properties.

Thus, to be able to show that the insertion of alternative photoinitiators in conjunction with third generation LEDs are able to increase the degree of conversion is a positive and relevant result for adhesive dentistry. The literature states, therefore, that the combination of alternative photoinitiators with the traditional camphorquinone/amine system improved the color stability of the model resin composites and maintaining their mechanical properties ${ }^{28,29}$.

Despite the important finding obtained in this study regarding DC, further physical, mechanical and biological properties should be investigated to strength the effect of alternative photoinitiators on the performance of dental adhesives. Indeed, since acidic monomers such as methacryloyloxydecyl hydrogen phosphate (MDP), and glycerol dimethacrylate phosphate (GDMA-P) have been included in dental adhesive systems with Bis-GMA and/ or HEMA ${ }^{30,31}$ further studies should be conducted to evaluate the DC exhibited by other formulations including acidic monomers and alternative photoinitiators. 
In conclusion, the use of alternative photoinitiators and polywave LED was found to improve the DC and decrease the yellowing effect of the experimental dental adhesive systems tested.

\section{Acknowledgements}

This study was not supported by any funding agency. All expenses were made through own initiative.

\section{References}

1. Sofan E, Sofan A, Palaia G, Tenore G, Romeo U, Migliau G. Classification review of dental adhesive systems: from the IV generation to the universal type. Ann Stomatol (Roma). 2017 Jul 3;8(1):1-17. doi: 10.11138/ads/2017.8.1.001.

2. Pena CE, Rodrigues JA, Ely C, Giannini M, Reis AF. Two-year randomized clinical trial of selfetching adhesives and selective enamel etching. Oper Dent. 2016 May-Jun;41(3):249-57. doi: 10.2341/15-130-C.

3. Vale MRL, Afonso FAC, Borges BCD, Freitas Jr AC, Farias-Neto A, Almeida EO, et al. Preheating impact on the degree of conversion and water sorption/solubility of selected single-bottle adhesive systems. Oper Dent. 2014 Nov-Dec;39(6):637-43. doi: 10.2341/13-201-L.

4. Barbosa MO, Carvalho RV, Demarco FF, Ogliari FA, Zanchi CH, Piva E, et al. Experimental self-etching HEMA-free adhesive systems: cytotoxicity and degree of conversion. J Mater Sci Mater Med. 2015 Jan;26(1):5370. doi: 10.1007/s10856-014-5370-6.

5. Neumann MG, Miranda Jr WG, Schmitt CC, Rueggeberg FA, Correa IC. Molar extinction coefficients and the photon absorption efficiency of dental photoinitiators and light curing units. J Dent. 2005 Jul;33(6):525-32.

6. Stansburry JW. Curing dental resins and composites by photopolymerization. J Esthet Dent. 2000;12(6):300-8.

7. Rueggeberg FA. Comtemporary issues in photocuring. Compend Contin Educ Dent Suppl. 1999;(25):S4-15; quiz S73.

8. Ilie N, Hickel R. Can CQ be completely replaced by alternative initiators in dental adhesives?. Dent Mater J. 2008 Mar;27(2):221-8.

9. Borges BCD, Sousa-Lima RX, Moreno GBP, Moreira DGL, Oliveira DCRS, Sousa-Junior EJ, Sinhoreti MAC. Polymerization and adhesion behavior of experimental dental bonding materials with different initiator systems. J Adhes Sci Tech. 2017;32(3):239-46. doi:10.1080/01694243.2017.1352839.

10. Asmussen E, Peutzfeldt A. Influence of composition on rate of polymerization contraction of light curing resin composites. Acta Odontol Scand. 2002 Jun;60(3):146-50.

11. Neumann MG, Schmitt CC, Ferreira GC, Correa IC. The initiating radical yields and the efficiency of polymerization for various dental photoinitiators excited by different light curing units. Dent Mater. 2006 Jun;22(6):576-84

12. Uhl A, Mills RW, Jandt KD. Photoinitiator dependent composite depth of cure and Knoop hardness with halogen and LED light curing units. Biomaterials. 2003 May;24(10):1787-95.

13. Rueggeberg FA. State-of-the-art: dental photocuring-a review. Dent Mater. 2011 Jan;27(1):39-52. doi:10.1016/j.dental.2010.10.021.

14. Busemann I, Lipke C, Schattenberg A, Willershausen B, Ernst CP. Shortest exposure time possible with LED curing lights. Am J Dent. 2011 Feb;24(1):37-44. 
15. Price RB, Fahey J, Felix CM. Knoop hardness of five composites cured with single-peak and polywave LED curing lights. Quintessence Int. 2010 Nov-Dec;41(10):e181-91.

16. Schroeder W, Arenas G, Vallo C. Monomer conversion in a light-cured dental resin containing 1-phenyl-1,2- propanedione photosensitizer. Polym Int. 2007 Sep;56(9):1099-105. doi: 10.1002/pi.2239.

17. Daood U, Swee Heng C, Neo Chiew Lian J, Fawzy AS. In vitro analysis of riboflavin-modified, experimental, two-step etch-and-rinse dentin adhesive: Fourier transform infrared spectroscopy and micro-Raman studies. Int J Oral Sci. 2015 Jun 26;7(2):110-24. doi: 10.1038/ijos.2014.49.

18. Ye Q, Park J, Topp E, Spencer P. Effect of photoinitiators on the in vitro performance of adentin adhesive exposed to simulated oral environment. Dent Mater. 2009 Apr;25(4):452-8. doi: 10.1016/j.dental.2008.09.011.

19. Ikemura K, Endo T. A review of the development of radical photopolymerization initiators used for designing light-curing dental adhesives and resin composites. Dent Mater J. 2010 Oct;29(5):481-501.

20. Sim JS, Seo HJ, Park JK, Garcia-Godoy F, Kim HI, Kwon YH. Interaction of LED lights with coinitiatorcontaining composite resins: effect of dual peaks. J Dent. 2012 Oct;40(10):836-42. doi: 10.1016/j. jdent.2012.06.008. Epub 2012 Jul 4

21. Segreto DR, Naufel FS, Brandt WC, Guiraldo RD, Correr-Sobrinho L, Sinhoreti MA. Influence of photoinitiator and light-curing source on bond strength of experimental resin cements to dentin. Braz Dent J. 2016 Jan-Feb;27(1):83-9. doi: 10.1590/0103-6440201600387.

22. Price RB, Felix CA. Effect of delivering light in specific narrow bandwidths from 394 to $515 \mathrm{~nm}$ on the microhardness of resin composites. Dent Mater. 2009 Jul;25(7):899-908. doi: 10.1016/j.dental.2009.01.098.

23. Rueggeberg FA, Margeson DH. The effect of oxygen inhibition on an unfilled/filled composite system. J Dent Res. 1990 Oct;69(10):1652-8.

24. Park YJ, Chae KH, Rawls HR. Development of a new photoinitiation system for dental light-cure composite resins. Dent Mater. 1999 Mar;15(2):120-7.

25. Borges BCD, Sousa-Junior EJ, Brandt WC, Loguercio AD, Montes MAJR, Puppin-Rontani RM, et al Degree of Conversion of Simplified Contemporary Adhesive Systems as Influenced by Extended Air-Activated or Passive Solvent Volatilization Modes. Oper Dent. 2012 May-Jun;37(3):246-52 doi: 10.2341/11-248-L.

26. Leal FB, Madruga FC, Prochnow EP, Lima GS, Ogliari FA, Piva E, et al. Effect of acidic monomer concentration on the dentin bond stability of self-etch adhesives. Int J Adhes Adhes. 2011 Sep;31(6):571-4. doi: 10.1016/j.jiadhadh.2011.05.007.

27. Schneider LF, Consani S, Sakaguchi RL, Ferracane JL. Alternative photoinitiator system reduces the rate of stress development without compromising the final properties of the dental composite. Dent Mater. 2009 May;25(5):566-72. doi: 10.1016/j.dental.2008.10.007.

28. Salgado VE, Borba MM, Cavalcante LM, Moraes RR, Schneider LF. Effect of photoinitiator combinations on hardness, depth of cure, and color of model resin composites. J Esthet Restor Dent. 2015 Mar-Apr;27 Suppl 1:S41-8. doi: 10.1111/jerd.12146.

29. Albuquerque PP, Moreira AD, Moraes RR, Cavalcante LM, Schneider LF. Color stability, conversion, water sorption and solubility of dental composites formulated with different photoinitiator systems. J Dent. 2013 Aug;41 Suppl 3:e67-72. doi: 10.1016/j.jdent.2012.11.020

30. Ganglione LA, Lima AF, Gonçalves LS, Cavalcanti AN, Aguiar FHB, Marchi GM. Mechanical properties and degree of conversion of etch-and-rinse and self-etch adhesive systems cured by a quartz tungsten halogen lamp and a light-emitting diode. J Mech Behav Biomed Mater. 2012 Aug;12:139-43. doi: 10.1016/j.jmbbm.2012.01.018.

31. Anchieta RB, Machado LS, Martini AP, Santos PH, Giannini M, Janal M, et al. Effect of long-term storage on nanomechanical and morphological properties of dentin-adhesive interfaces. Dent Mater 2015 Feb;31(2):141-53. doi: 10.1016/j.dental.2014.11.010 